\title{
A biomechanical comparison of two cephalomedullary nails; one using a single lag screw with antirotator blade and a nail using two lag screws for unstable intertrochanteric fractures
}

\section{Mehmet Salih Soylemez ${ }^{1}$, Burak Ozturan ${ }^{2}$, Ismail Turkmen $^{3}$, Selim Erturk ${ }^{4}$, Fuat Akpinar ${ }^{2}$, Bülent Kilic ${ }^{5}$, Murat Demiroglu ${ }^{2} *$ Korhan Ozkan ${ }^{2}$}

\author{
${ }^{1}$ Department of Orthopaedics and Traumatology, Bingol State Hospital, Bingol, Turkey \\ ${ }^{2}$ Department of Orthopaedics and Traumatology, Istanbul Medeniyet University, Goztepe Training and Research \\ Hospital, Istanbul, Turkey \\ ${ }^{3}$ Department of Orthopaedics and Traumatology, Beykoz State Hospital, Istanbul, Turkey \\ ${ }^{4}$ Department of Material and Metalurgia Engineering, Istanbul Technical University, Istanbul, Turkey \\ ${ }^{5}$ Department of Health Sciences, Istanbul Gelisim University, Orthopaedic Surgeon, Istanbul, Turkey
}

Received: 15 July 2016

Accepted: 23 July 2016

\section{*Correspondence:}

Dr. Murat Demiroglu,

E-mail: drmuratdemiroglu@gmail.com

Copyright: () the author(s), publisher and licensee Medip Academy. This is an open-access article distributed under the terms of the Creative Commons Attribution Non-Commercial License, which permits unrestricted non-commercial use, distribution, and reproduction in any medium, provided the original work is properly cited.

\begin{abstract}
Background: Implant choice for fixation of intertrochanteric fractures remains controversial despite being one of the most commonly performed operations. Although use of sliding hip screws is still considered a gold standard in treatment of these fractures, there is a wide tendency in using cephalomedullary nails because of their biomechanical superiority over sliding hip screws. This trial was initiated in order to compare the biomechanical properties of two different cephalomedullary nails, aPFN and the PROFIN under axial loading, based on the questions that can a single lag screw with an antirotator blade render better rotational stability? Is there a difference between one lag screw or two lag screws with respect to superior migration or cut-out of the screws? And do different nail designs cause different types of failure and what are the pros and cons of classical and new designs from the view point of biomechanical aspects?

Methods: Ten pairs of third generation synthetic bone models simulating unstable intertrochanteric fracture were used for biomechanical testing.

Results: No posterior displacement of screws was recorded in both groups suggesting rotational unstability. There was not a significant difference between forces values loaded at the time of failure.

Conclusions: Although there was no statistically significant difference between compressive strengths at the time of failure, aPFN may provide equal rigid fixation with less possible cut-out which may have an important consequences in real clinical applications.
\end{abstract}

Keywords: Intertrochanteric fracture, Cephalomedullary nail, Antirotator blade, Single lag screw

\section{INTRODUCTION}

Implant choice for fixation of intertrochanteric fractures remains controversial despite being one of the most commonly performed operations. Although use of sliding hip screws (SHSs) is still considered a gold standard in treatment of these fractures, there is a wide tendency in using cephalomedullary nails because of their 
biomechanical superiority over SHS. $^{1,2}$ Besides, a cephalomedullary nail can be inserted by a minimally invasive technique, as the closed reduction of the fracture preserves the haematoma and minimally invasive technique allows the surgeon to minimise soft-tissue dissection, thereby reducing surgical trauma, blood loss, infection and wound complications. ${ }^{3,4}$

Starting from introduction of gamma nails, different designs of cephalomedullary nails have been used in these fractures to improve functional results and decrease the complications. In 1997 AO/ASIF had developed proximal femoral nail (PFN) which had been used frequently and its similar designs have still been used especially in developing countries. ${ }^{3,5-7}$ Because of biomechanical complications caused by two lag screws, proximal femoral nail antirotation (PFNA) was developed in 2004. ${ }^{8,9}$ PFNA uses one helical blade to prevent rotational instability and maintain fracture stability with one implant in the femoral head. However after introduction of PFNA, different cephalomedullary nail designs using one lag screw have been developed to facilitate fracture fixation and reduce the biomechanical complications due to implant designs and optimize the fracture healing.

In this study we compare fixation stability characteristics between two different cephalomedullary nail designs, a nail using two lag screws (PROFIN, TST san. Istanbul, Turkey) and a nail using one telescoping lag screw with an antirotator blade (aPFN, TST san. Istanbul, Turkey). Ten pairs of third generation synthetic bone models simulating unstable intertrochanteric fracture were used for biomechanical testing.

\section{METHODS}

20 third-generation femur models which resembles osteoporotic bone were provided simulating AO/Orthopedic Trauma Association type 31/A2 unstable intertrochanteric fractures (Synbone ${ }^{\circledR}$, no: 2420, Switzerland). The characteristics of the bone models used were as follows: Length: $337 \mathrm{~mm}$, neck angle: $135^{\circ}$, anteversion: $15^{\circ}$, head diameter: $48 \mathrm{~mm}$, and canal diameter: $10 \mathrm{~mm}$. Models were coated with a synthetic cortical layer and filled with dense foam representing cancellous bone. Femoral bone models were divided into two groups, each comprised of ten bones.

An antirotator proximal femoral nail (aPFN) (TST SAN, Istanbul, Turkey) was implanted into the femurs in the first group. The proximal diameters of the aPFNs were 15 $\mathrm{mm}$, and the distal diameters were $10 \mathrm{~mm}$. The nail had a slot at the distal end, a $6^{\circ}$ of proximal medio-lateral curvature and a neck-shaft angle of $135^{\circ}$. An appropriatesized drill was used before inserting the nails. The size of the nail was selected to be $10 \mathrm{~mm} \times 220 \mathrm{~mm}$. After the insertion of the intramedullary nail, in accordance with the proximal femoral anatomy, one lag screw $(10.0 \mathrm{~mm}$ diameter, $85 \mathrm{~mm}$ length, cancellous and having a canal where the antirotator blade sits) was placed at $15^{\circ}$ anteversion through the targeting device of the nail under the control of a fluoroscopy. Next, antirotator blade was inserted from the inferior surface of the screw where it sits and locks to the nail and the screw. Nail was fixed distally through distal dynamic hole using a $5.0 \mathrm{~mm}$ cortical screw through the targeting device. At the last step a $6.0 \mathrm{~mm}$ cannulated compression screw (provides $6 \mathrm{~mm}$ compression and prevents lateral migration of antirotator blade) was added to the back of the lag screw and it was locked (Figure 1). The same procedure was repeated for the remaining 9 bone models by a single surgeon.

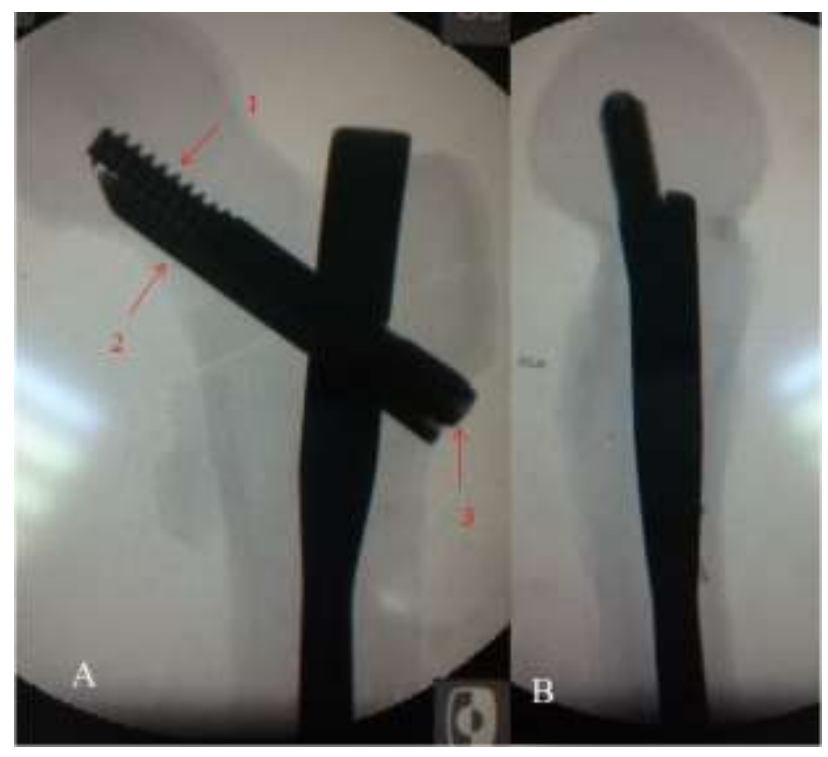

Figure 1: Anterior-posterior and lateral $x$-ray images of the aPFN applied fractured femur model. Red arrows, 1) Lag screw 2) Antirotator blade 3) Cannulated compression screw.

A proximal femoral intramedullary nail (PROFIN) (TST SAN, Istanbul, Turkey) was placed into the femurs in the second group. The proximal diameters of the PROFINs were $16 \mathrm{~mm}$, and the distal diameters were $10 \mathrm{~mm}$. Also this nail had a slot at the distal end, a $6^{\circ}$ of proximal medio-lateral curvature and a neck-shaft angle of $135^{\circ}$. An appropriate-sized drill was used before inserting the nails. The size of the nail was selected to be $10 \mathrm{~mm} \times 220 \mathrm{~mm}$ as it was in the first group. After insertion of the intramedullary nail, in accordance with the proximal femoral anatomy, two lag screws $(8.5 \mathrm{~mm}$ diameter, $85 \mathrm{~mm}$ length, cancellous) were placed at $15^{\circ}$ anteversion through the targeting device of the nail under the control of a fluoroscopy. Nail was fixed distally through distal dynamic hole using a $3.5 \mathrm{~mm}$ cortical screw through the targeting device (Figure 2). The same procedure was repeated for the remaining 9 bone models by the same surgeon. Fluoroscopy images before and after the loading tests and images of fractured regions of the bone models were obtained and recorded. 

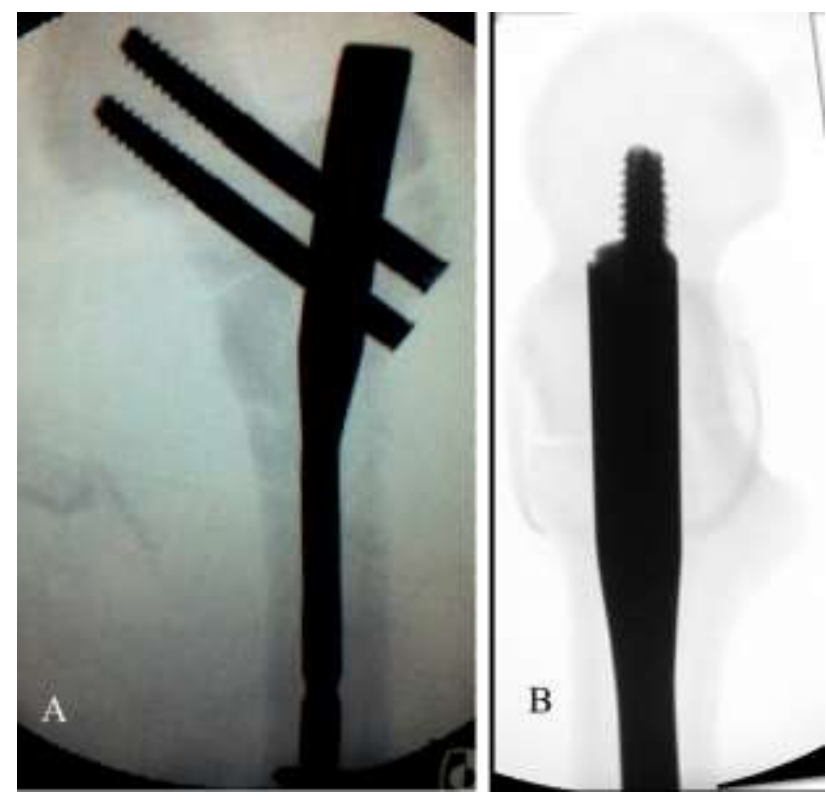

Figure 2: Anterior-posterior and lateral x-ray images of the PROFIN applied fractured femur model.

The Shimadzu autograph AGS testing device was used to measure the compressive strength of the specimens. The biomechanical loading test was performed by the same metallurgical and materials engineer under the supervision of the orthopedic surgeon. Bone models were placed in accordance with the mechanical axis of the femur and force was loaded in this axis onto the femoral heads. Each specimen was initially loaded with $500 \mathrm{~N}$ and an axial force at a constant velocity of $5 \mathrm{~mm} / \mathrm{min}$ was loaded until failure. Force values at fracture time were recorded.

Descriptive analysis was performed using the SPSS®, version 23.0 (IBM Corporation, Armonk, New York, United States). Independent-samples T-test with Bootstrap results were used to compare the independent two groups. Shapiro-Wilk test was used to examine the suitabilty of distrubution of data. Levene test was used to examine the homogeneity of variences. A P-value of $<0.05$ was considered to be statistically significant for all analyses.

\section{RESULTS}

In the aPFN group fracture patterns were as follows; fracture occurred at the trochanter major and then the shaft was fractured at the tip of the nail and near to the distal locking screw in 2 specimens (specimens 5, 7) (Figure 3), fracture occurred at the tip of the nail and near the distal locking screw in 8 specimens (specimens $2-4$, 6, 8-10) (Figure 4).

In PROFIN group fracture patterns were as follows; femoral head splitting fracture occurred while shaft remains intact in 3 specimens (specimens 1, 8, 9) (Figure 5), fracture occured at the trochanter major and then shaft was fractured at the tip of the nail and near the distal locking screw in 1 specimen (specimens 2), fracture occurred at the tip of the nail and near the distal locking screw in 6 specimens (specimens 3-7, 10) (Figure 4).
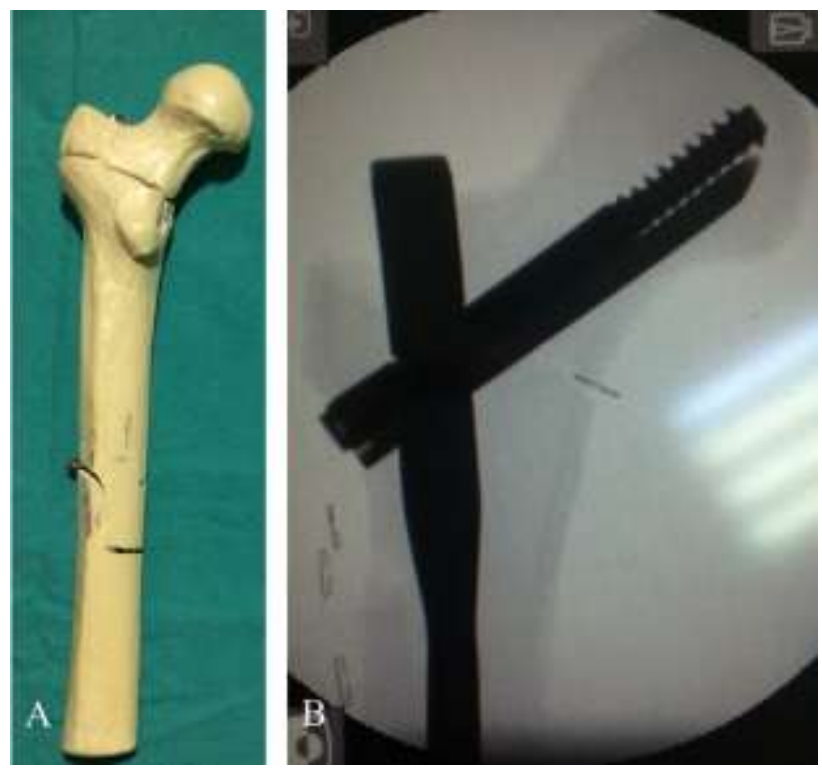

Figure 3: Trochanter major fracture in aPFN group (specimen 5), (a) Fracture occurred at the trochanter major and tip of the nail. (b) x-ray image showing no superior migration of the lag screw.
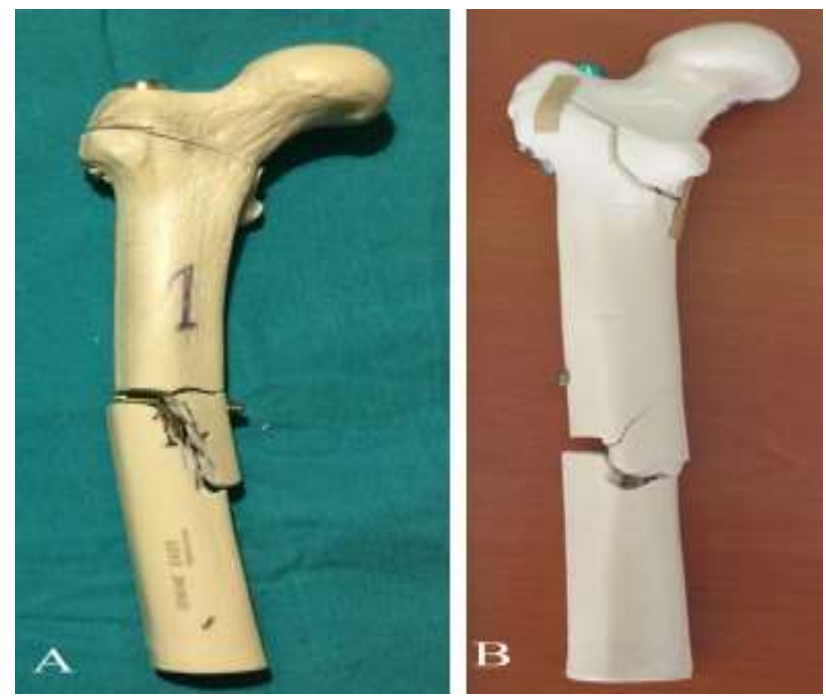

Figure 4: (a) Fracture occurred at the tip of the nail in aPFN group (specimen 2), (b) Fracture occurred at the tip of the nail in PROFIN group (specimen 3 ).

There was no posterior or superior migration on $\mathrm{x}$-rays obtained after testing for the aPFN group (Figure 3). However, cut-out of the lag screws was detected in 3 speciemens in PROFIN group (Figure 5). No posterior or superior migration was detected on x-rays of remaining 7 specimens. Mean force loaded at the time of fracture was $1637.30 \pm 82.89 \mathrm{~N}$ in the aPFN group and 1559.35 \pm 225.84 $\mathrm{N}$ in the PROFIN group (Table 1, 2 and 3, Figure 6). 

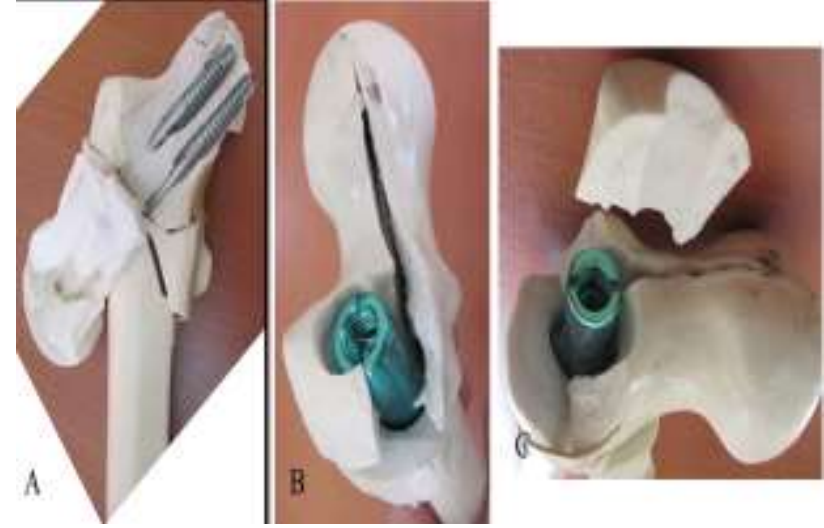

Figure 5: Femoral head fracture in PROFIN group (a) specimen 1, (b) specimen 8 and (c) specimen 9.

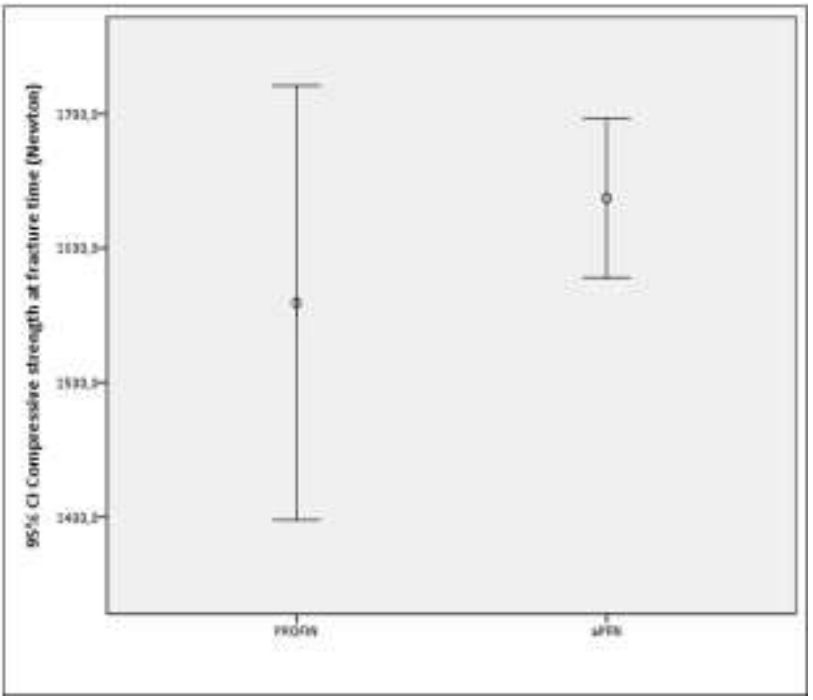

Figure 6: Graphic showing distribution of force values at the time of fracture for both groups.

Although there was no significant difference between two groups in the means of compressive strength at fracture time $(p=0.320)$ (Table 3$)$. Mean force loaded at the time of fracture was higher in aPFN group comparing to PFN group. Likewise, no significant difference between compressive strength of models that sustained fracture at the tip of the nail, or sustained a fracture at trochanter major or femoral head in both groups was found (respectively $\mathrm{p}=0.290, \mathrm{p}=0.310$ ). There was no lateral migration of lag screws in both groups.

Table 1: Compression results of aPFN added models.

\begin{tabular}{|lll|}
\hline $\begin{array}{l}\text { No of } \\
\text { Specimen }\end{array}$ & $\begin{array}{l}\text { Compressive } \\
\text { strength at } \\
\text { fracture time } \\
\text { (Newton) }\end{array}$ & $\begin{array}{l}\text { Compressive } \\
\text { strength at } \\
\text { fracture time } \\
\text { (Kg-force) }\end{array}$ \\
\hline 1 & 1795.5 & 183.09 \\
\hline 2 & 1549.5 & 158.06 \\
\hline 3 & 1643.5 & 175.03 \\
\hline 4 & 1599.3 & 172.64 \\
\hline 5 & 1669.1 & 171.26 \\
\hline 6 & 1736.9 & 177.12 \\
\hline 7 & 1557.6 & 158.82 \\
\hline 8 & 1569.4 & 160.03 \\
\hline 9 & 1573.8 & 160.48 \\
\hline 10 & 1678.4 & 171.14 \\
\hline
\end{tabular}

Table 2: Compression results of the PROFIN added bone models.

\begin{tabular}{|lll|}
\hline $\begin{array}{l}\text { No. of } \\
\text { Specimen }\end{array}$ & $\begin{array}{l}\text { Compressive } \\
\text { strength at } \\
\text { fracture time } \\
\text { (Newton) }\end{array}$ & $\begin{array}{l}\text { Compressive } \\
\text { strength at } \\
\text { fracture time } \\
\text { (Kg-force) }\end{array}$ \\
\hline 1 & 1601.5 & 163.30 \\
\hline 2 & 1595.0 & 162.64 \\
\hline 3 & 1580.0 & 161.11 \\
\hline 4 & 1199.0 & 122.26 \\
\hline 5 & 1359.0 & 138.57 \\
\hline 6 & 1299.0 & 132.46 \\
\hline 7 & 1910.0 & 194.76 \\
\hline 8 & 1505.0 & 153.46 \\
\hline 9 & 1795.0 & 183.03 \\
\hline 10 & 1750.0 & 178.45 \\
\hline
\end{tabular}

Table 3: Statistical analysis results comparing the forces applied to the two groups.

\begin{tabular}{|c|c|c|c|c|}
\hline Compressive strength & PROFIN & aPFN & Total & P-value \\
\hline \multicolumn{5}{|l|}{ (Newton) } \\
\hline Mean \pm SD & $1559.35 \pm 225.84$ & $1637.30 \pm 82.89$ & $1598.33 \pm 170.33$ & \multirow{2}{*}{0.320} \\
\hline Mxm-Mnm & 1910-1199 & $1795.5-1549.5$ & 1910-1199 & \\
\hline \multicolumn{5}{|l|}{ (Kg-force) } \\
\hline Mean \pm SD & $159.00 \pm 23.03$ & $168.77 \pm 8.82$ & $163.89 \pm 17.70$ & \multirow{2}{*}{0.228} \\
\hline Mxm-Mnm & $194.76-122.26$ & $183.09-158.06$ & $194.76-122.26$ & \\
\hline
\end{tabular}

Independent T Test(Bootstrap) SD: Standard deviation $\quad$ Mxm-Mnm: Maximum-Minimum 


\section{DISCUSSION}

This trial was initiated in order to compare the biomechanical properties of two different cephalomedullary nails, aPFN and the PROFIN under axial loading, based on the questions that can a single lag screw with an antirotator blade render better rotational stability? Is there a difference between one lag screw or two lag screws with respect to superior migration or cutout of the screws and? Do different nail designs cause different types of failure and what are the pros and cons of classical and new designs from the view point of biomechanical aspects?

Maintaining rotational stability is the rationale behind using two lag-screws in treatment of unstable intertrochanteric fractures. ${ }^{10}$ However after introduction of PFN several studies have reported complications related to two lag screws. Cut-out, Z- effect, reverse Zeffect, lateral migration of the screws are the mostly reported complications resulting from inappropriate placement of screws, low- bone mineral density and alteration of the weight on the lag screws during weight bearing cycles. ${ }^{9,11,12}$ Different screw combinations and designs have been developed to overcome these problems and improve the success of treatment.

Single helical-shaped blade in cephalomedullary nails have been developed to resist cutting out was introduced in recent years. By inserting the blade into the femoral head, the surrounding trabecular structure would undergo a volumetric compaction. Theoretically it offers the potential of resisting rotation and a better holding power in osteoporotic femoral head with compaction of cancellous bone and can decrease the rate of cutting out. ${ }^{13,14}$ As a matter of fact, several clinical and experimental studies were published after introduction of the single helical blade. Although studies comparing two lag screws with a single helical blade concluded the biomechanical and clinical superiority of single helical blade. ${ }^{3,13-15}$ There are still unresolved problems like lack of compression with blade and more lateral migration when compared with telescoping screws. ${ }^{16}$

The aPFN have been developed from this point of view. The $10 \mathrm{~mm}$ telescoping screw with a larger transverse area has been developed to resist cutting out. Besides, threads have the advantage of compression if desired. The antirotator blade fits into the inferior surface of the screw and impacts trabecular bone to resist rotation and locks the screw to resist lateral migration.

X-rays after testing were evaluated for both groups in our study. Three specimens sustaining head splitting fracture were recorded as cut-out (PROFIN group). Although no posterior or superior displacement in any of the remaining specimens were noted, we believe that speciemens that sustained trochanter major fracture (two in aPFN group an one in PROFIN group) and then shaft fracture, may have undergone a minimal superior migration of lag screws. In these three specimens compressive strength at the failure time were detected to be similar and all sustained a shaft fracture eventually.

Previous biomechanical studies comparing biomechanical properties of lag screw applied fractured femoral models have been cut too near to the tip of the nail distally to prevent a femoral shaft fracture and examine only failures caused by lag screws. ${ }^{13,17,18}$ But we believe that this situation doesn't simulate the real stance. Because load to failure under such a condition eventually leads a failure from femoral head. However under physiological loads failure can occur at any place of the femur and this can be due to implant or other physiological circumstances. In our study specimens were long enough to examine possible shaft fractures. However all of the models in aPFN group and 6 of the PROFIN group were fractured from the tip of the nail under similar load values

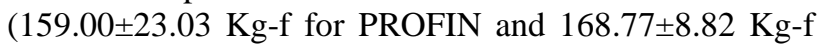
for aPFN). Suggesting that failure at the tip of the nail is more likely to occur with usage of cephalomedullary nails rather than failures caused by lag screws. Femoral head splitting fracture had occurred in three of PROFIN group. We believe that this can be result of superior positioning of the proximal lag screw which has been shown to be the main reason of cut-out. In a finite element analyses of two lag screws compared with one screw Wang et al had showed that the smaller diameter two screws develop increased stresses in the bone of the femoral head, which potentially could lead to premature screw cut-out. ${ }^{11}$

Another issue making treatment of intertrochanteric femur fractures challenging is excessive forces exerted to the femoral head. Cephalomedullary nails have been designed to provide controlled impaction by transforming these forces into a compressor force on fracture site. ${ }^{19}$ Although there is no evidence we believe that maintaining compression at fracture site adds to the reduction quality and resistance to torsional forces. Although compression can be maintained in both nail designs used in this study, no compression was achieved in either group. Because force was loaded only in axial direction.

Apart from the nail design, the surgical tecnique is very important for the treatment success. ${ }^{20}$ When using two lag screws besides anatomical fracture reduction, insertion of the inferior lag screw as close as possible to inferior cortex of the femoral neck is strongly recommended as the tensile and compressive trabecula of the proximal femur intersect at that area so making this place for the strongest screw purchase, but unfortunately it may not be always possible to place inferior lag screw in proper place due to anatomical and surgeon experience. ${ }^{7,20}$ Also in patients with small femoral neck diameter it may sometimes be very hard to find enough space for two screw insertion. 


\section{CONCLUSION}

In our study, design parameters of both nails excluding lag screws were similar. No posterior displacement of screws was recorded in both groups suggesting rotational unstability. There was not a significant difference between force values loaded at the time of failure. Although there was no statistically significant difference between compressive strengths at the time of failure, aPFN may provide equal rigid fixation whith less possible cut-out which may have an important consequences in real clinical applications.

This study has some limitations. First, although third generation synthetic bones are validated in use of biomechanical tests comparing biomechanical properties of two different implants, it would be better if the test was done using cadaveric bones. ${ }^{13}$ Although study reflects the biomechanical properties of two different designs of cephalomedullary nails, it should have been better if the failure test was done using cyclical loading which had been more similar to physiological loading of daily activities. Only axial loading was performed which makes it harder to draw conclusions about endurance and biomechnical properties of implants under bending and torsional forces. The sample size is small. Further clinical correlations with large multicentric randomized controlled studies are required.

\section{ACKNOWLEDGEMENTS}

Authors would like to thanks to "TST san" for providing the nails which has been used in this study.

Funding: No funding sources

Conflict of interest: None declared

Ethical approval: The study was approved by the institutional ethics committee

\section{REFERENCES}

1. Queally JM, Harris E, Handoll HH, Parker MJ. Intramedullary nails for extracapsular hip fractures in adults. Cochrane Database Syst Rev. 2014;12(9):CD004961.

2. Jones HW, Johnston P, Parker M. Are short femoral nails superior to the sliding hip screw? a metaanalysis of 24 studies involving 3,279 fractures. Int Orthop. 2006;30(2):69-78.

3. Mereddy P, Kamath S, Ramakrishnan M, Malik H, Donnachie N. The AO/ASIF proximal femoral nail antirotation (PFNA): a new design for the treatment of unstable proximalfemoral fractures. Injury. 2009;40(4):428-32.

4. Radford PJ, Needoff M, Webb JK. A prospective randomised comparison of the dynamic hip screw and the gamma locking nail. J Bone Joint Surg Br. 1993;75:789-93.

5. Alyassari G, Langstaff RJ, Jones JW, Allami M. The AO/ASIF proximal femoral nail (PFN) for the treatment of unstable trochanteric femoral fracture. Injury.2002;33:395-9.

6. Tasyıkan L, Ugutmen E, Sanel S, Soylemez MS, Ozkan K, Solakoglu C. Short-term results of surgical treatment with cephalomedullary nails for basicervical proximal femoral fractures. Acta Orthop Belg. 2015;81(3):427-34.

7. Ozkan K, Unay K, Demircay C, Cakir M, Eceviz E. Distal unlocked proximal femoral intramedullary nailing for intertrochanteric femur fractures. Int Orthop. 2009;33(5):1397-400.

8. Windolf J, Hollander DA, Hakimi M, Linhart W. Proximal femoral nail (PFN): pitfalls and complications in the use of the proximal femoral nail. Langenbecks Arch Surg. 2005;390:59-65.

9. Schipper IB, Steyerberg EW, Castelein RM, Heijden FH, Hoed PT, Kerver AJ, et al. Treatment of unstable trochanteric fractures. Randomised comparison of the gamma nail and the proximalfemoral nail. $\mathrm{J}$ Bone Joint Surg $\mathrm{Br}$. 2004;86(1):86-94.

10. Gardenbroek TJ, Segers MJ, Simmermacher RK, Hammacher ER. The proximal femur nail antirotation: an identifiable improvement in the treatment of unstable pertrochanteric fractures? J Trauma. 2011;71(1):169-74.

11. Wang CJ, Brown CJ, Yettram AL. Intramedullary femoral nails: one or two lag screws? a preliminary study. Med Eng Phys. 2000;22:613-24.

12. Boldin C, Seibert FJ, Fankhauser F, Peicha G, Grechenig W, Szyszkowitz R. The proximal femoral nail (PFN)-a minimal invasive treatment of unstable proximal femoral fractures: a prospective study of 55 patients with a follow up of 15 months. Acta Orthop Scand. 2003;74:53-8.

13. Luo Q, Yuen G, Lau TW, Yeung K, Leung F (2013) A biomechanical study comparing helical blade with screw design for sliding hip fixations of unstable intertrochanteric fractures. Scientific World Journal. 2013:1-6.

14. AO/ASIF PFNA. Leading the way to optimal stability: Synthesis original instruments and implants of the association for the study of internal fixation. AO/ASIF. Stratec Medical. 2004:1-44.

15. Penzkofer J, Mendel T, Bauer C, Brehme K. Treatment results of pertrochanteric and subtrochanteric femoral fractures: a retrospective comparison of PFN and PFNA. Unfallchirurg. 2009;112(8):699-705.

16. Schwarzkopf R, Takemoto RC, Kummer FJ, Egol KA. Helical blade vs telescoping lag screw for intertrochanteric fracture fixation. Am J Orthop. 2011;40(9):452-6.

17. Strauss E, Frank J, Lee J, Kummer FJ, Tejwani N. Helical blade versus sliding hip screw for treatment of unstable intertrochanteric hip fractures: a biomechanical evaluation. Injury. 2006;37(10):9849.

18. Kubiak EN, Bong M, Park SS, Kummer F, Egol K, Koval KJ. Intramedullary fixation of unstable 
intertrochanteric hip fractures: one or two lag screws. J Orthop Trauma. 2004;18(1):12-7.

19. Bong MR, Patel V, Iesaka K, Egol KA, Kummer FJ, Koval KJ. Comparison of a sliding hip screw with a trochanteric lateral support plate to an intramedullary hip screw for fixation of unstable intertrochanteric hip fractures: a cadaver study. J Trauma. 2004;56(4):791-4.

20. Poyanli OS, Soylemez S, Ozkut AT, Uygur E, Kemah B, Unal OK. Precise placement of lag screws in operative treatment of trochanteric femoral fractures with a new guide system. Injury. 2015;46(11):2190-5.

Cite this article as: Soylemez MS, Ozturan B, Turkmen I, Erturk S, Akpinar F, Kilic B, et al. A biomechanical comparison of two cephalomedullary nails; one using a single lag screw with antirotator blade and a nail using two lag screws for unstable intertrochanteric fractures. Int J Res Orthop 2016;2:63-9. 